\title{
Activity patterns of African buffalo Syncerus caffer in the Lower Sabie Region, Kruger National Park, South Africa
}

\author{
S.J. RYAN and W. JORDAAN
}

Ryan, S.J. and W. Jordaan. 2005. Activity patterns of African buffalo Syncerus caffer in the Lower Sabie Region, Kruger National Park, South Africa. Koedoe 48(2): 117-124. Pretoria. ISSN 0075-6458.

\begin{abstract}
The activity budgets of three herds of African buffalo in the Lower Sabie region of Kruger National Park, recorded between 1991 and 1992 were quantified to examine both nocturnal and seasonal effects on feeding activity and 24-hr movement in an area of dense bushveld. We found that the average $24-\mathrm{hr}$ distance traveled by herds $(3.35 \mathrm{~km})$ was shorter than that found in other studies and that there was no seasonal effect on this distance, which we attribute to ready availability of water in both seasons. We found that the buffalo spent a similar amount of time feeding $(9.5 \mathrm{hrs})$ as in other studies, but that the proportional feeding and resting time was influenced by the time of day and the season. These herds spent proportionally more time feeding at night (44.5\% vs $32.0 \%$ ) and more time resting in the day $(28.4 \%$ vs $16.0 \%)$. In addition, they appeared to rest more during the day and feed more at night during the wet season, when it was hotter.
\end{abstract}

Keywords: African buffalo, Syncerus caffer, activity budgets, Kruger National Park

S.J. Ryan, Department of Environmental Science, Policy \& Management, 137 Mulford Hall, University of California at Berkeley, Berkeley, CA 94720, USA (sjryan@nature.berkeley.edu) (Present address: Museum of Vertebrate Zoology, 3101 Valley Life Sciences Building, University of California at Berkeley, Berkeley, CA 94720, USA); W. Jordaan, 3 Conservation Services, SANParks, Private Bag X402, Skukuza, 1350 Republic of South Africa.

\section{Introduction}

Mammalian herbivores spend the majority of their time feeding; as Beekman \& Prins (1989) pointed out, horses spend more than $70 \%$ of their time grazing and cattle, $50-60 \%$. Ruminant ungulates must additionally allocate time to ruminating and resting. In savanna ecosystems, ruminants must not only obtain sufficient quality and quantity of food, but may also need to adjust their activity budget as seasonal changes constrain when the activity can take place in a 24-hour period.

African buffalo Syncerus caffer are large grazers, whose feeding ecology predicts greater selection of high biomass (OwenSmith 1988; Redfern et al. 2003) than high quality grass swards. Additionally, Redfern et al. (2003) have shown empirically that buffalo select for areas close to water sources in Kruger National Park. Thus the feeding and ranging behavior of buffalo is subject to constraints such as the abundance of grass and the availability of water. In previous studies, seasonal changes in vegetation quality and water availability have been shown to alter both ranging and feeding habits of buffalo (Funston et al. 1994).

In this study, we describe activities and behaviors of three breeding herds of buffalo in a semi-arid wooded savanna environment. This study contrasts with prior studies of buffalo which tend to focus on diurnal behaviour in open savanna habitats (Funston et al. 1994; Prins 1996; Sinclair 1977; Winterbach \& Bothma 1998), as herds were tracked in relatively dense bushveld. Moreover, this study comprises 24-hour samples, meaning that nocturnal behavior of buffalo was also quantified. In addition, this data was collected during a severe drought period, such that there was less rainfall occurring than in prior 


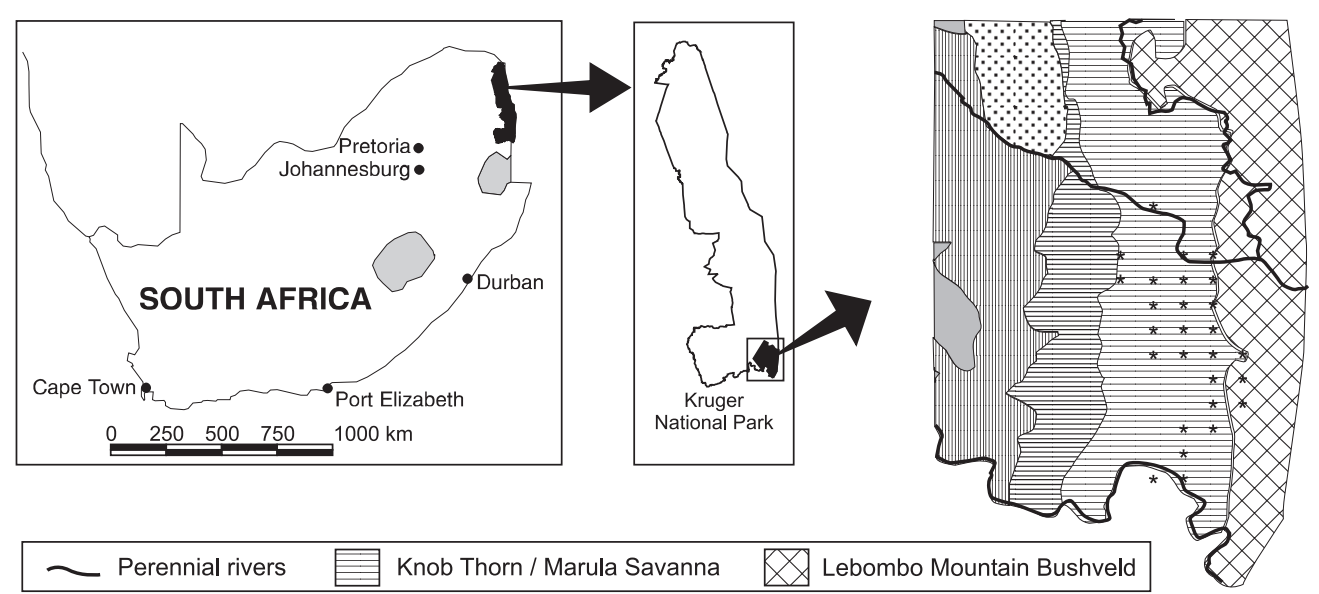

Fig. 1. The Lower Sabie region of Kruger National Park. Detail shows locations of observations (asterisks) on a coarse $(5 \mathrm{~km})$ grid; the ecozones and three perennial river courses are also shown.

studies at similar latitude (Funston et al. 1994).

Buffalo groups were followed in the Lower Sabie region of Kruger National Park, South Africa. Tracking data from radio-collared individuals and visual observations were used to describe daily ranging activity, and scan sampling was used to describe daily herd activity between 1991 and 1992. Differences in activity budgets, timing of activity during the day and ranging observed in buffalo are hypothesised to arise due to seasonal and habitat differences (Funston et al. 1994). We explore both diurnal and nocturnal activities, seasonal differences and compare this study with others in different habitats.

\section{Study Site}

The data used in this study were collected in the Lower Sabie region of Kruger National Park (Fig. 1). The study area spans two ecozones: Knobthorn/Marula Savanna and Lebombo Bushveld (Gertenbach 1983). The data was collected in an area bordered at $\left(31.90^{\circ},-25.11^{\circ}\right)-\left(32.00^{\circ},-25.35^{\circ}\right)$; all data was recorded in the WGS84 datum. This region receives $400-500 \mathrm{~mm}$ of rain a year on average, and the rainfall and temperature follow a unimodal distribution, which leads to a warm wet season (Oct-Mar) and a cool dry season (Apr-Sep) (Gertenbach 1980).

\section{Methods}

\section{Herd Activity Data}

Data was collected on three herds that were tracked using radio telemetry and visual observations. The herds were estimated at approximately 400, 200 and 250 animals, respectively. Fifteen separate focal samples of activity were taken between March 1991 and August 1992. Seven of these samples were $\geq 24 \mathrm{hrs}$ in duration and eight were $\geq 11 \mathrm{hrs}$ of daytime observations. Main herd activity was sampled at 5-minute intervals during the day and night, where possible.

Herd activities recorded were:

1. Feeding - stand/walk and eat

2. Standing - standing with head up and ruminating

3. Resting - standing or lying with head bent downwards, not eating

4. Moving - walking but not grazing

5. Drinking - drinking water or standing $<10 \mathrm{~m}$ from water. 
Table 1

An ANOVA and Tukey-Kramer's Honest Significant Difference (HSD) post-hoc means test of the diurnal activity budgets of buffalo herds; the percent of observation time in each sample with the standard error (SE) and the conversion of these means and errors into hours are included

\begin{tabular}{llllll}
\hline Activity & HSD* & \multicolumn{2}{c}{$\begin{array}{c}\text { Observation } \\
\text { time (SE) }\end{array}$} & \multicolumn{2}{c}{$\begin{array}{c}\text { Approx } \\
\text { hours }\end{array}$} \\
& & SE) \\
\hline Feeding & A & 37.47 & $(2.62)$ & 4.50 & $(0.31)$ \\
Standing & B & 28.78 & $(2.14)$ & 3.45 & $(0.26)$ \\
Resting & B & 25.86 & $(2.71)$ & 3.10 & $(0.33)$ \\
Moving & C & 5.22 & $(1.56)$ & 0.63 & $(0.19)$ \\
Drinking & C & 2.66 & $(0.64)$ & 0.32 & $(0.08)$ \\
\hline
\end{tabular}

*Activities with different letters have significantly different means

ANOVA: $\mathrm{F}=54.07, d f=4, p=0.0001$

\section{Herd Movement Data}

Using radio telemetry, locations of herds during 40 separate days were collected over the study period (dry season, $n=24$ days; wet season, $n=16$ days). These locations were used to calculate the distance traveled by the herd during each day's sample. Due to sampling time differences (range: 13-29 hrs), the distance estimate from each data collection was multiplied by $24 \div$ (observation time (hrs)) to estimate a 24-hr distance. As this is simply a difference in location over an elapsed time, this represents a minimum distance estimate. We pooled all herds and types in the study to obtain an average daily movement estimate. These estimates were compared by season using a Welch modified $t$-test for unequal variances.

\section{Herd Activity}

To examine diurnal activity of buffalo herds, we cropped the 24-hr samples to $12 \mathrm{hrs}$ and analysed all 15 samples together. Due to unequal observation times, we converted hours of activity into proportions of the total. An ANOVA with post-hoc means tests (Tukey-Kramer's Honest Significant Difference Test, $\alpha=0.05$, Table 1) was used to determine both the order of times allocated to each activity and which activity occupied significantly more of the time than others. We also used the 24-hr sample data to quantify the mean time spent by the herd in each activity during the full day (Table 2).

We used the longer activity budgets to compare diurnal and nocturnal activity budgets of buffalo. Due to differences in the hour of sunset in the datasets, we
Table 2

An ANOVA and Tukey-Kramer's Honest Significant Difference (HSD) post-hoc means test of the 24-hr activity budgets of buffalo herds; the percent of observation time in each sample with the standard error (SE) and the conversion of these means and errors into hours are included

\begin{tabular}{|c|c|c|c|}
\hline Activity & $\mathrm{HSD}^{*}$ & $\begin{array}{c}\% \text { Observation } \\
\text { time }(\mathrm{SE})\end{array}$ & $\begin{array}{c}\text { Approx } \\
\text { hours (SE) }\end{array}$ \\
\hline Feed & A & $39.41(2.21)$ & $9.46 \quad(0.53)$ \\
\hline Standing & B & 31.49 (1.69) & $7.56 \quad(0.40)$ \\
\hline Resting & $\mathrm{C}$ & $21.45(2.36)$ & $5.15(0.57)$ \\
\hline Moving & $\mathrm{D}$ & $4.76 \quad(0.90)$ & $1.14(0.22)$ \\
\hline Drinking & $\mathrm{D}$ & $2.88 \quad(0.51)$ & $0.69 \quad(0.12)$ \\
\hline
\end{tabular}

*Activities with different letters have significantly different means

ANOVA: $\mathrm{F}=90.21, d f=4, p=0.0001$

chose 19:00 $(7 \mathrm{pm})$ as the division in the dataset. Welch modified ANOVAs for unequal variances were used to compare means. Significant results were further tested to examine whether differential activity might occur as a result of seasonality.

Activity timing was quantified by pooling all herd activity budgets. The proportion of observations within each 5-minute scan corresponding to activities $1-5$ were plotted against time (Fig. 4). Activity periods were defined for activities $1-3$ as periods of time when the proportion exceeded $20 \%$. For activities 4 and 5, the activity periods were both of short duration and infrequent in occurrence, such that a single herd engaging in the activity might comprise the entire occurrence. Furthermore, this might appear as five separate observations within a few hours and thus appear to be a repeated low proportion activity. We took clusters of activity observations, rather than the proportion to represent activity periods and descriptively reported the timing of these activities.

\section{Results}

\section{Herd Movement Data}

The mean $24 \mathrm{hr}$ estimated minimum distance traveled by all herds pooled was $3.35 \pm$ $0.35 \mathrm{~km}(x \pm \mathrm{SE})$. A Welch modified $t$-test did not detect a significant seasonal difference in 
the 24-hr distance estimates (Wet: $3.14 \mathrm{~km}$, Dry: $3.49 \mathrm{~km} ; t=0.4547, d f=26.022, p=$ $0.6531)$.

\section{Herd Activity}

Analysis of the diurnal activity of all herds showed that significantly more time was devoted to activity 1 , i.e., feeding, than other activities. The herds spent an average of $37.5 \%$ or $4.5 \mathrm{hrs}$ of the day actively feeding, and another $28.8 \%$ (approx. $3.5 \mathrm{hrs)}$ to standing and ruminating; and resting took another $25.9 \%$ (approx. $3.1 \mathrm{hrs}$ ) of the day. This shows us that $75 \%$ or 9 hrs of the day is devoted to obtaining and ruminating food (Table 1). Using the seven 24-hr samples, we found a similar breakdown of activity pattern, but the relative proportion of time spent feeding (1) and standing (2) increased and the other activities showed a corresponding decrease in proportions (see Table 2).

When we compared diurnal and nocturnal components of the herd activity budget, we found that the buffalo spent a significantly greater proportion of time feeding (\#1) during the night $[44.5 \%$ vs $32.0 \%(\mathrm{~F}=9.85$, $d f=1, p=0.009)]$; and a trend towards a greater proportion of time resting (\#3) during the day $[28.4 \%$ vs $16.0 \%(\mathrm{~F}=3.61, d f=1$, $p=0.08)]$. We found no significant proportional differences in diurnal and nocturnal time budget for other activities (Fig. 2). Due to low sample size, we could not detect seasonal effects on overall activity budgets. However, in Fig. 3 there is a trend suggesting that buffalo spend more time feeding during the dry season than the wet, more time moving around and less time resting. Although the sample size was too small for rigorous testing, we sought to find seasonal differences in diurnal and nocturnal behaviour. The difference between day and night feeding and resting activities was not statistically significant, although the data suggest a trend toward a greater proportion of nocturnal feeding and resting in the wet season (Feeding (\#1), Dry Season: $\mathrm{F}=2.61, p=0.16$; Wet Season: $\mathrm{F}=8.48, p=0.07$; Resting (\#3), Dry Season $\mathrm{F}=0.21, p=0.67$; Wet Season:

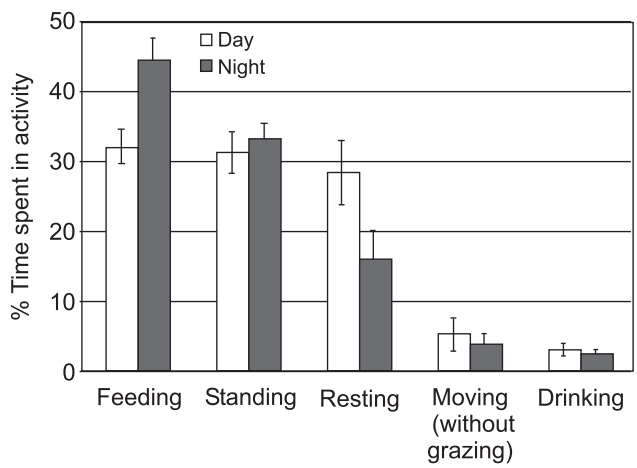

Fig. 2. Relative proportions of time allocated by the buffalo herds to activities, diurnal (white) and nocturnal (black) components, with their standard errors (SE).

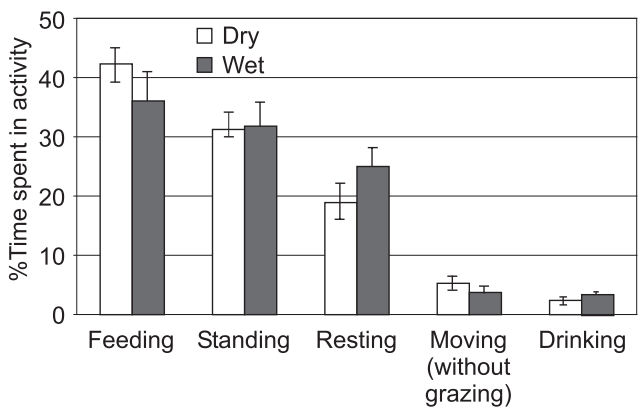

Fig. 3. Relative proportions of time allocated by the buffalo herds to activities, dry season (white) and wet season (black) components, with their standard errors (SE).

$\mathrm{F}=6.31, p=0.07)$. All other potential seasonal effects were not statistically significant.

Figure 4 shows the relative proportions of each activity in each 5-minute interval in the upper panel; in the lower panel we show the corresponding number of observations in each 5-minute interval. Due to differences in the start and end time of the diurnal observation sessions, the number of observations within the 5-minute time intervals increase in the early morning and decrease towards evening. The nocturnal observation ses- 


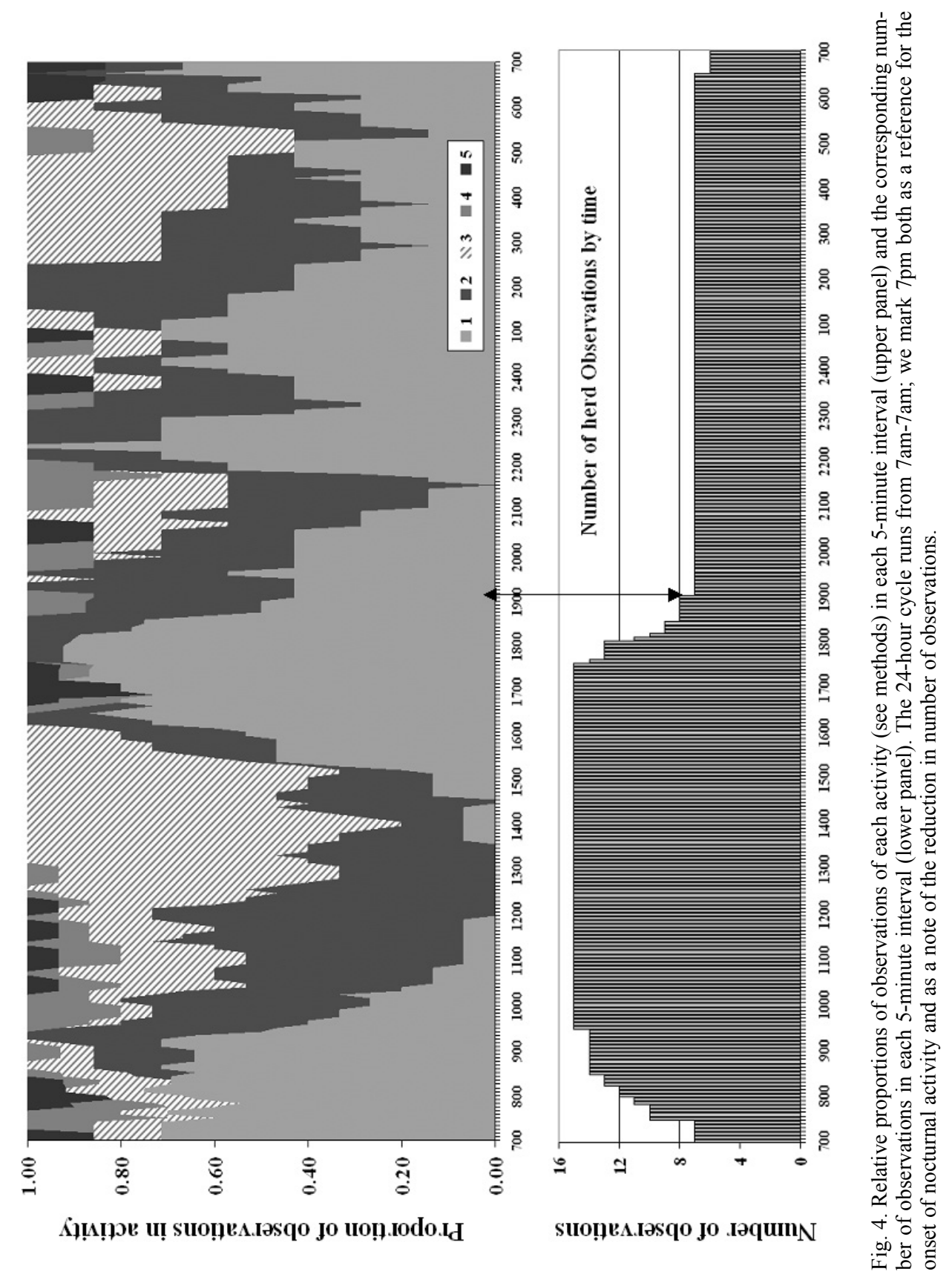


sions, although fewer in number, have a consistent number of observations per scan. The 24-hour cycle runs from 7am-7am; we marked $7 \mathrm{pm}$ both as an indicator of the onset of nocturnal activity and of the reduction in number of observations. We found that the buffalo had two defined feeding (\#1) periods during the day and into the night (approximately 5:30-10:30; peak: 9:15 and 15:00-21:00; peak: 17:10), and less defined but moderate continuous feeding during the night hours and into the dawn. We see that standing (\#2), contributes a large proportion of the observations during and following the feeding bouts (8:15-13:50 and 18:00-24:00), and as feeding does, it continues at moderate levels throughout. Resting (\#3) has a clear daytime peak, with a major bout occurring from 12:00-16:00, and another moderate bout occurring in the early morning (3:006:00). Moving (\#4) appears to occur in two clusters; one in the mid-morning to early afternoon between 10:00 and 13:00 and another cluster in the evening to night at 19:00-22:00; drinking (\#5) occurs in an early morning cluster around 6:00-8:00 and another mid-morning cluster from 10:00-12:00; a couple of observations occur later in the day also and two toward the middle of the night.

\section{Discussion}

In this study, the estimated minimum distance that the buffalo herds traveled in $24 \mathrm{hrs}$ was $3-4 \mathrm{~km}$. This did not change between seasons, suggesting that these buffalo have high site fidelity, perhaps due to a combination of the constraint of artificial water availability and the presence of reliable grazing resources.

In Cameroon, Stark (1986) found that buffalo moved around $7 \mathrm{~km}$ in the wet season and $5.6 \mathrm{~km}$ in the dry; Grimsdell \& Field (1976) reported $9.6 \mathrm{~km}$ on average in Rwenzori National Park, Uganda; Conybeare (1980) reported $6.1 \mathrm{~km}$ on average in the dry season in Sengwa Wildlife Research Area, Zimbabwe. Funston et al. (1994) found that in the early wet season the herds in the Sabie Sand reserve (on the western edge of Kruger
National Park) tended to remain in an area around a watering hole for up to eight days and then move. They noted also that in the dry season, the herd would make long distance $(10 \mathrm{~km})$ movements at night in search of better grazing. The present study took place in a more closed habitat than a majority of these prior studies, and the high density of artificial water availability in KNP (Brits et al. 2002) might reduce the need for wide ranging in this habitat. Moreover, there are three perennial river courses running through this study area (see Fig. 1); and buffalo herds tend to maintain smaller home ranges where there are perrennial rivers Hunter (1996). As this study was conducted during a drought period, these river courses may have dried out and served as areas retaining green grass swards, a reliable source of grazing, but not providing sufficient drinking areas. Thus, the buffalo may have been constrained by artificial water presence instead and behaved similarly to the study animals of Funston et al. (1994). We cannot compare our measure directly with the daily tracking data of prior studies, as it is not representative of a full grazing path route, rather the shortest distance between radio tracking locations. However, it provides us with a range approximation for the area.

We found that feeding comprised around $9.5 \mathrm{hrs}(39.41 \%)$ on average of the $24-\mathrm{hr}$ activity budget (Table 2). This falls within the range for grazing found by both Grimsdell \& Field (1976) (9 hrs) and Sinclair's (1977) bachelor bull study in the Serengeti (9.7-10.1 hrs). This compares with the $40 \%$ estimated by Winterbach \& Bothma (1998). We found that across both seasons, the buffalo herds appeared to spend a greater proportion of time feeding at night than during the day, similar to the buffalo at Lake Manyara, Tanzania (Beekman et al. 1989) and as seen by Sinclair (1977) in the Serengeti, although his observations occurred in the wet season, not the dry. Stark (1986) estimated that during dry season, his study herd of savanna buffalo (Syncerus caffer brachyceros) grazed for an average of $3.1 \mathrm{hrs}(\sim 26 \%)$ in a $12-\mathrm{hr}$ period. This is 
considerably less than the average for our study herds. In addition, as suggested by Sinclair (1977), we saw a trend toward more time spent feeding in the dry season than the wet, perhaps in response to lower vegetation quality and quantity. We also saw a trend toward more time moving in the dry season, which may reflect searching for feeding patches; concomitant with this was less resting, perhaps a repercussion of spending more time looking for food.

We saw that the buffalo tended to spend time feeding and standing in succession (Fig. 4), with standing and ruminating occupying around $30 \%$ of observed activity time, both diurnally and nocturnally (Tables 1 \& 2). While this provided time for rumination, it is likely a combination of both rumination and vigilance behaviour. Buffalo exhibit standing, raised head vigilance; it is plausible that they are not only using visual cues, but also olfactory. We see that this activity occurs in greater proportion at night (Fig. 2), although this is not statistically significant. We posit that with a reduction in visibility at night more vigilance will be necessary. As this data was collected in non-exclusive categories, we can assume that the proportion of time spent being vigilant is higher than simply the time allocated to the standing (\#2) category. Buffalo were recorded as resting (\#3) while standing, if they were not feeding. This suggests that vigilant behaviour may comprise a significant proportion of buffalo activity.

We found that the buffalo grazed in two major daytime periods, which is consistent with the findings of Winterbach et al. (1998). We also found that they continued to graze moderately throughout the night. We saw that buffalo tended to rest more during the day than at night, particularly during the warm wet season. As found in other studies (Stark 1986; Winterbach et al. 1998), the herds had a long mid-day rest period, after the morning grazing peak as shown in Fig. 4. Sinclair (1977) showed that grazing activity ceased completely in buffalo at a certain elevated ambient temperature. Thus we would expect the buffalo to cease grazing and to rest when the temperature is hottest-midday in the warm wet season.

We found that the buffalo herds had two main periods of diurnal drinking, which occurred in the early morning and midmorning, after a grazing bout and while ruminating. There appears to be more time devoted to drinking during the day than at night, but we found no evidence to suggest that they spent more time drinking during the dry season than the wet. Previous studies have suggested that buffalo only need to drink once a day (e.g. Sinclair 1977). Winterbach \& Bothma (1998) found that buffalo drank in the early afternoon, whereas Grimsdell \& Field (1976) found that they drank in the mid-morning. Since we did not distinguish between drinking and standing near water, it is not clear how often these herds drank each day. This system has a high density of available water sources, so buffalo may drink more than once in a day. Qualitative observations (WJ) suggest that buffalo will stand in the water, but only a few herd members will drink at one time.

\section{Future Directions}

This data represents only 15 sampling periods in total, which was not sufficient to demonstrate seasonal differences in buffalo herd activity budgets, but provided a baseline to inform future data collection. In future studies, we would suggest additional observation sessions, spread more evenly across a year to encompass both seasons appropriately. This study presented an opportunity to refine activity categories; in particular, the overlap in potentially important behaviours between categories, such as vigilance, can inform category definitions. The categories of activity such as standing and resting were both likely during ongoing rumination, but this distinction made it harder to compare with prior studies. In the future, the addition of samples across the year will provide more detailed comparisons and will allow further exploration of the flexibility of activity budgets as buffalo adjust to seasonal changes. The interest in 
nocturnal activity suggests that additional long observation sessions such as these will provide valuable information regarding buffalo ecology. Furthermore, with the advent of more sophisticated tracking devices, such as GPS collars, the combination of geographic locations and activity observations can be better used, in conjunction, to understand buffalo feeding ecology.

\section{Acknowledgements}

Thank you to Kruger National Park's Scientific Services for permission to carry out this study. Thanks to A.G. Vaughan for help with data formatting, and to three reviewers for comments and edits. S.J. Ryan's research was supported by EPA-STAR fellowship FP-916382.

\section{References}

Beekman, J.H. \& H.H.T. Prins. 1989. Feeding strategies of sedentary large herbivores in EastAfrica, with emphasis on the African buffalo, Syncerus caffer. African Journal of Ecology 27: 129-147.

Brits, J., M.W. VAN Rooyen \& N. VAN Rooyen. 2002. Ecological impact of large herbivores on the woody vegetation at selected watering points on the eastern basaltic soils in the Kruger National Park. African Journal of Ecology 40: 53-60.

Conybeare, A. 1980. Buffalo numbers, home range and daily movement in the Sengwa Wildlife Research Area, Zimbabwe. South African Journal of Wildlife Research 10: 89-93.
Funston, P.J., J.D. SkinNer, \& H.M. DotT. 1994. Seasonal-variation in movement patterns, homerange and habitat selection of buffalos in a semiarid habitat. African Journal of Ecology 32: $100-114$.

GERTENBACH, W.P.D. 1980. Rainfall patterns in the Kruger National Park. Koedoe 23: 35-44.

GertenbaCH, W.P.D. 1983. Landscapes of the Kruger National Park. Koedoe 6: 9-122.

GRIMSDELl, J.J.R. \& C.R. FIELD. 1976. Grazing patterns of buffaloes in the Rwenzori National Park, Uganda. East African Wildlife Journal 14: 339-344.

HunTER, C.G. 1996. Land uses on the Botswana/ Zimbabwe border and their effects on buffalo. South African Journal of Wildlife Research 26: 136-150.

Owen-Smith, R.N. 1988. Megaherbivores: the influence of very large body size on ecology. Cambridge: University Press.

PRINS, H.H.T. 1996 Ecology and behaviour of the African buffalo: social inequality and decision making. New York, NY.: Chapman \& Hall.

Redfern, J.V., R. Grant, H. BigGs, \& W.M. Getz. 2003. Surface-water constraints on herbivore foraging in the Kruger National Park, South Africa. Ecology 84: 2092-2107.

SinCLAIR, A.R.E. 1977. The African buffalo: a study of resource limitation of populations. Chicago: University of Chicago Press.

STARK, M.A. 1986. Daily movement, grazing activity and diet of savanna buffalo, Syncerus caffer brachyceros, in Benoue-National-Park, Cameroon. African Journal of Ecology 24: 255-262.

Winterbach, H.E.K. \& J. DU P. Bothma. 1998. Activity patterns of the Cape buffalo Syncerus caffer caffer in the Willem Pretorius Game Reserve, Free State. South African Journal of Wildlife Research 28: 73-81. 